\title{
Introduction to Homogenous Catalysis with Ruthenium-Catalyzed Oxidation of Alcohols: An Experiment for Undergraduate Advanced Inorganic Chemistry Students
}

\author{
John R. Miecznikowski \\ Fairfield University, jmiecznikowski@fairfield.edu \\ John P. Caradonna \\ Kathleen M. Foley \\ Paniel this Kwiecien anditior
}

Gepygiglpt Rigi 1 The American Chemical Society.

This is the author's pre-print version submitted for publication. The subsequent publication can be found at Journal of Chemical Education, 2011, 88 (5), pp. 657-661. DOI: 10.1021/ed1001575 See next page for additional authors

\section{Repository Citation}

Miecznikowski, John R.; Caradonna, John P.; Foley, Kathleen M.; Kwiecien, Daniel J.; Lisi, George P.; and Martinez, Anthony M., "Introduction to Homogenous Catalysis with Ruthenium-Catalyzed Oxidation of Alcohols: An Experiment for Undergraduate Advanced Inorganic Chemistry Students" (2011). Chemistry \& Biochemistry Faculty Publications. 11.

https://digitalcommons.fairfield.edu/chemistry-facultypubs/11

\section{Published Citation}

Miecznikowski, J.R.*; Caradonna, J.P.; Foley, K.M.; Kwiecien, D.J.; Lisi, G.P.; Martinez, A.M. "Introduction to Homogenous Catalysis with Ruthenium-Catalyzed Oxidation of Alcohols: An Experiment for Undergraduate Advanced Inorganic Chemistry Students ." Journal of Chemical Education, 2011, 88 (5), pp. 657-661

This item has been accepted for inclusion in DigitalCommons@Fairfield by an authorized administrator of DigitalCommons@Fairfield. It is brought to you by DigitalCommons@Fairfield with permission from the rightsholder(s) and is protected by copyright and/or related rights. You are free to use this item in any way that is permitted by the copyright and related rights legislation that applies to your use. For other uses, you need to obtain permission from the rights-holder(s) directly, unless additional rights are indicated by a Creative Commons license in the record and/or on the work itself. For more information, please contact digitalcommons@fairfield.edu. 


\section{Authors}

John R. Miecznikowski, John P. Caradonna, Kathleen M. Foley, Daniel J. Kwiecien, George P. Lisi, and Anthony M. Martinez 


\title{
Introduction to Homogenous Catalysis: Ruthenium Catalyzed Oxidation of Alcohols
}

An experiment for undergraduate Advanced Inorganic Chemistry Students

John R. Miecznikowski, ${ }^{\ddagger}$ * John P. Caradonna ${ }^{\S}$, Kathleen M. Foley ${ }^{\ddagger}$, Daniel J. Kwiecien ${ }^{\ddagger}$, George P. Lisi ${ }^{\ddagger}$, and Anthony M. Martinez $z^{\ddagger}$.

${ }^{\ddagger}$ Department of Chemistry and Biochemistry, Fairfield University, 1073 North Benson Road, Fairfield, CT 06824; imiecznikowski@fairfield.edu

$\S$ Department of Chemistry, Boston University, 590 Commonwealth Avenue, Boston, MA 02215

\begin{abstract}
A three-week laboratory experiment, which introduces students in Advanced Inorganic Chemistry to air sensitive chemistry and catalysis, is described. During the first week, the students synthesize $\mathrm{RuCl}_{2}\left(\mathrm{PPh}_{3}\right)_{3}$. During the second and third weeks, the students characterize the formed coordination compound and use it as a precatalyst for the oxidation of 1-phenylethanol to acetophenone. The synthesized $\mathrm{RuCl}_{2}\left(\mathrm{PPh}_{3}\right)_{3}$ is characterized using ${ }^{1} \mathrm{H}$ and ${ }^{31} \mathrm{P}$ NMR Spectroscopies, IR Spectroscopy, and magnetic susceptibility. The students run catalytic and control reactions and determine the percent yield of the product using ${ }^{1} \mathrm{H}$ NMR. The synthesis and catalytic conditions are modified from previously published research articles. The $\mathrm{RuCl}_{2}\left(\mathrm{PPh}_{3}\right)_{3}$ complex is air sensitive and is prepared under a nitrogen gas atmosphere and worked up in an inert atmosphere glove box. The catalytic and control reactions are set up in the inert atmosphere glove box and carried out at reflux outside of the glove box under a nitrogen gas atmosphere. In this laboratory, the students learn how to set up and run a reaction under a nitrogen atmosphere. The students also learn how to work in a glove box and how to set up and characterize catalytic and control reactions.
\end{abstract}




\section{Keywords}

Inorganic Chemistry, Laboratory Instruction, Catalysis, Coordination Compounds, Oxidation/reduction, Alcohols, IR Spectroscopy, Magnetic Properties, NMR Spectroscopy. 


\section{Lab Summary}

This article presents a description of an Advanced Inorganic Chemistry experiment, which involves synthesizing an air-sensitive coordination compound and using it as a precatalyst in an oxidation reaction. There are two primary reasons why this experiment was developed and implemented. The first is the desire for undergraduate chemistry majors to have experience in working with vacuum and inert atmosphere systems. (1) The second is a need for students to have exposure to catalysis in the laboratory. (1) Both of these outcomes are in accord with the recommendations of the American Chemical Society's Committee on Professional Training. (1)

In this experiment, the students prepare $\mathrm{RuCl}_{2}\left(\mathrm{PPh}_{3}\right)_{3}$ and use this complex as a precatalyst for the oxidation of an alcohol. (2) The alcohol is oxidized following a transfer hydrogenation process. (3) Over the past three years, I have refined the synthesis and use of $\mathrm{RuCl}_{2}\left(\mathrm{PPh}_{3}\right)_{3}$ as a precatalyst for the oxidation of alcohols in the Advanced Inorganic Chemistry Laboratory at Fairfield University. The complex, $\mathrm{RuCl}_{2}\left(\mathrm{PPh}_{3}\right)_{3}$ is sensitive to air so the catalytic reactions are set up in an inert atmosphere glove box. The laboratory is performed over three consecutive four hour laboratory periods and the students work in pairs. In the first week, the students synthesize $\mathrm{RuCl}_{2}\left(\mathrm{PPh}_{3}\right)_{3}$ and in the second and third weeks the students characterize the formed complex and carry out control and catalytic reactions.

This laboratory accomplishes several important goals: it introduces students to an air sensitive synthesis; it gives students experience in working in an inert atmosphere glove box; $(4,5)$ it gives students experience in characterizing their formed complex using ${ }^{1} \mathrm{H}$ and ${ }^{31} \mathrm{P}$ NMR spectroscopies, IR spectroscopy, and magnetic susceptibility; it gives them experience in setting up and running catalytic and control reactions, specifically the catalytic oxidation of 1-phenylethanol to acetophenone; and it gives students experience in analyzing their products from their catalytic reactions and control reactions using ${ }^{1} \mathrm{H}$ NMR spectroscopy and calculating the turnover frequency (TOF) of their precatalyst. The laboratory is reliable and safe and the chemicals required for the laboratory 
are relatively inexpensive. The students enjoy working in the glove box and performing catalytic reactions that are being utilized in research. The students learn how to measure mass and volume and perform filtrations within the glove box. The students also learn how to use the antechamber to bring materials into and out of the glove box, how the $\mathrm{Cu}(\mathrm{I})$ catalyst scrubs oxygen from the box and how molecular sieves work to remove water from the box. (4) The lab instructor prepared all of the solvents used within the glove box by subjecting them to at least six successive freeze-pump-thaw cycles.

\section{Background}

Transfer hydrogenation is defined as "the reduction of multiple bonds with the aid of a formal hydrogen atom donor in the presence of a catalyst," as shown in equation 1. (6)

$$
\mathrm{A}+\mathrm{DH}_{2} \rightarrow \mathrm{AH}_{2}+\mathrm{D}
$$

In equation $1, \mathrm{DH}_{2}$ donates $\mathrm{H}^{+}$and $\mathrm{H}^{-}$to $\mathrm{A}$.

Catalytic hydrogen transfer can be applied to either reduction or oxidation reactions. In this laboratory, we will focus on catalytic oxidation reactions.

Ruthenium, rhodium and iridium metal complexes have been reported for catalytic hydrogen transfer. Complexes containing these metals are most common for transfer hydrogenation. (7) Palladium, copper, titanium, molybdenum, tungsten, and rhenium metal complexes have also been reported for catalytic dehydrogenation. (7)

In a homogeneous hydrogen transfer oxidation reaction, acetone is utilized as both a solvent and a hydrogen acceptor (equation 2).

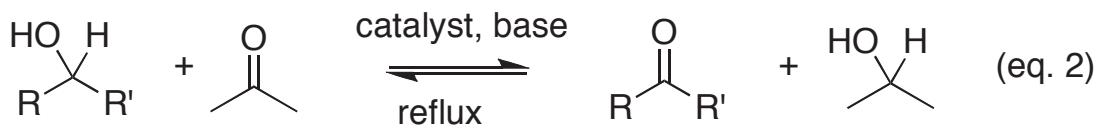

Since most hydrogen transfers are thermodynamically driven processes, acetone is present in a large excess to drive the reaction to completion. Acetone is easy to handle (b.p. $56{ }^{\circ} \mathrm{C}$ ), inexpensive, unreactive towards most functional groups, 
and dissolves many organic compounds. Acetone will be reduced to 2-propanol, (b.p. $82^{\circ} \mathrm{C}$ ), which can be easily removed from the reaction mixture.

The addition of base is necessary when acetone is used as a hydrogen acceptor. The alcohol substrate must be deprotonated to form an alkoxide (see mechanism) and moves the equilibrium towards the formation of the alkoxide. Bäckvall and Crabtree have independently utilized potassium carbonate and other carbonate bases for transfer hydrogenation. $(3,8)$

Mechanism: (9)

Bäckvall et al. have proposed a mechanism for the oxidation of alcohols using ruthenium complexes (Scheme 1). (10)

Scheme 1: Proposed catalytic cycle for the dehydrogenation of alcohols by acetone in the presence of $\mathrm{RuCl}_{2}\left(\mathrm{PPh}_{3}\right)_{3}$.

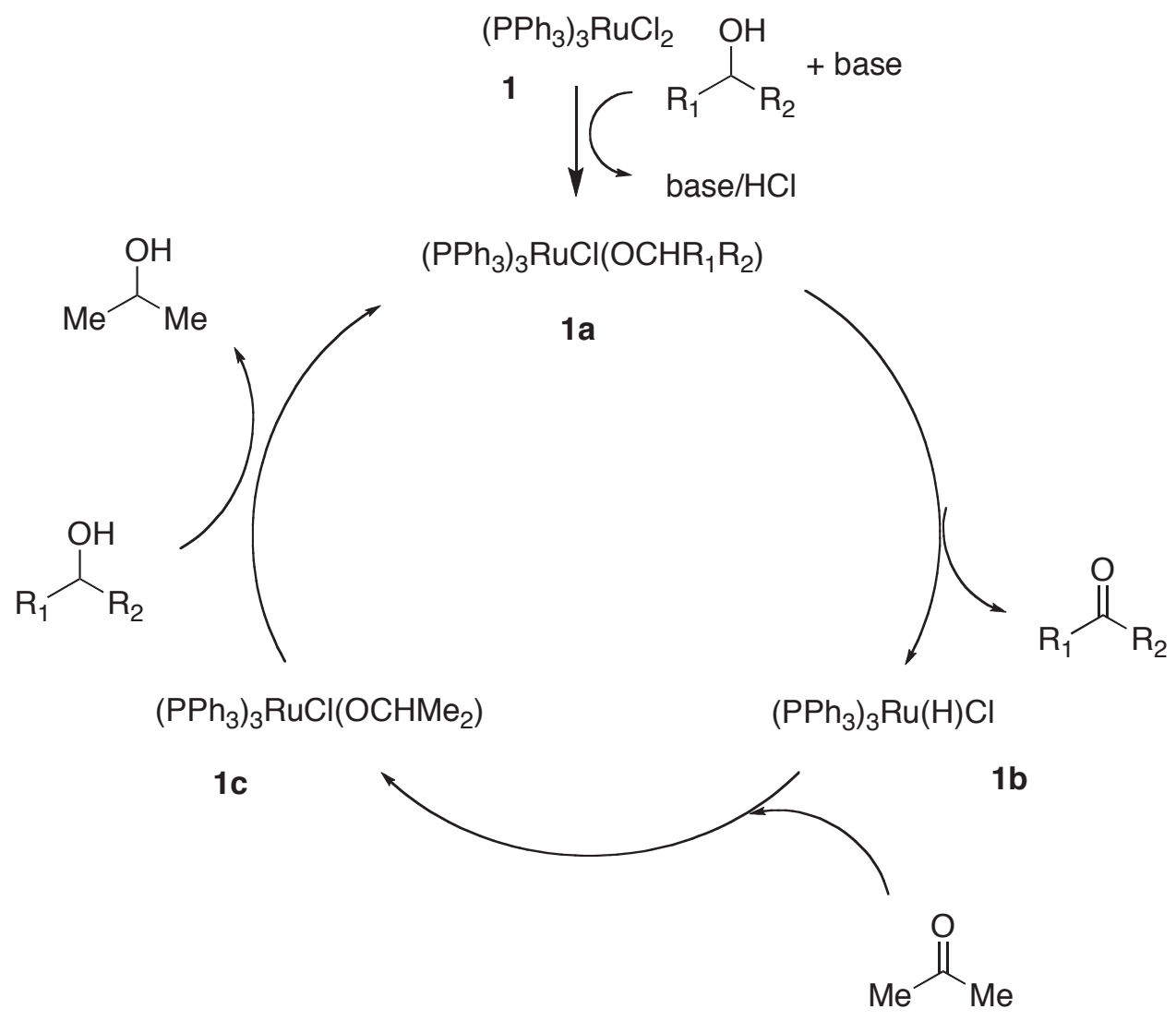


In the first step of the proposed mechanism, the base, $\mathrm{K}_{2} \mathrm{CO}_{3}$, deprotonates the alcohol substrate and a ruthenium alkoxide, $1 \mathrm{a}$, is formed. Next, a $\beta$-hydride elimination happens to produce a carbonyl compound and a ruthenium hydride, $\mathbf{1 b}$. This hydride compound can then react with acetone, the hydrogen acceptor, via insertion of the acetone in the ruthenium hydride bond to produce another ruthenium alkoxide complex, 1c. An exchange reaction of 1c with a molecule of the substrate alcohol gives 2-propanol and $1 \mathrm{a}$ is regenerated. The function of the base, $\mathrm{K}_{2} \mathrm{CO}_{3}$, is to form the initial nucleophilic alkoxide.

\section{Experimental Procedure}

Synthesis of $\mathrm{RuCl}_{2}\left(\mathrm{PPh}_{3}\right)_{3}:(2)$

$$
\mathrm{RuCl}_{3} \cdot \mathrm{xH}_{2} \mathrm{O}+\mathrm{nPPh}_{3} \rightarrow\left[\mathrm{RuCl}_{2}\left(\mathrm{PPh}_{3}\right)_{3}\right]+\text { other products (eq. 3) }
$$

In a typical reaction, a three-necked $100 \mathrm{~mL}$ round bottom flask is charged with ruthenium trichloride trihydrate $\left(2.00 \times 10^{-3}\right.$ moles $)$, a stir bar, and methanol $(20 \mathrm{~mL})$. This solution is refluxed under nitrogen gas for 5 minutes in a sand bath. Two necks are stoppered and a reflux condenser is attached to the third neck. The nitrogen gas is connected to the top of the reflux condenser. The reaction mixture is allowed to cool to room temperature and triphenylphosphine $\left(1.20 \times 10^{-2}\right.$ moles $)$ is added to the reaction mixture. This brown solution is refluxed under nitrogen gas for 2.5 hours. During this time, a brown precipitate forms. The reaction is allowed to cool to room temperature, purged with nitrogen gas and then brought into the glove box.

The precipitate is collected by gravity filtration (filter paper \# 1) using a conical funnel in the glove box. The resulting brown solid is washed with diethyl ether ( $3 \mathrm{x}, 15 \mathrm{~mL}$ each) and is stored in the glove box.

Characterization of $\mathrm{RuCl}_{2}\left(\mathrm{PPh}_{3}\right)_{3}$ :

The students characterize the complex using ${ }^{1} \mathrm{H}$ and ${ }^{31} \mathrm{P}$ NMR (in $\mathrm{CDCl}_{3}$ ), IR spectroscopy, and magnetic susceptibility. The NMR, and magnetic susceptibility samples are prepared inside the glove box. 
Typical Procedure for Catalytic Reaction:

In the glove box, a triple neck $100 \mathrm{~mL}$ round bottom flask is charged with $\mathrm{RuCl}_{2}\left(\mathrm{PPh}_{3}\right)_{3}\left(1.2 \times 10^{-4}\right.$ moles $)$, and $\mathrm{K}_{2} \mathrm{CO}_{3},\left(1.0 \times 10^{-3}\right.$ moles $)$ and a stir bar. Then, in the glove box, the substrate for catalysis, 1-phenylethanol, $\left(1.0 \times 10^{-3}\right.$ moles) and the internal standard mesitylene $\left(1.0 \times 10^{-3}\right.$ moles $)$ are then carefully added to a vial followed by $15 \mathrm{~mL}$ of dry acetone. This acetone solution is then added to the round bottom flask and the reaction solution becomes yellow/brown in color. A green reaction solution indicates that the $\mathrm{RuCl}_{2}\left(\mathrm{PPh}_{3}\right)_{3}$ has oxidized. The round bottom flask is capped with rubber stoppers and the round bottom is removed from the glove box.

The round bottom is then carefully and quickly attached to a reflux condenser under a positive pressure of nitrogen gas and the contents are refluxed under nitrogen using a sand bath.

After $1 \mathrm{~h}$ and $2 \mathrm{~h}$ of heating under reflux, aliquots of the reaction solution ( 2 $\mathrm{mL}$ ) are removed using a syringe and a needle and added to about $50 \mathrm{~mL}$ of $\mathrm{n}$ hexane in order to quench the reaction. The hexane/reaction mixture is then filtered through Celite, which is packed into a conical funnel. The solvent is removed under reduced pressure using a rotary evaporator to yield a dark brown oil.

Characterization of Catalytic Reactions:

The ${ }^{1} \mathrm{H}$ NMR of the reaction mixture is measured after $1 \mathrm{~h}$ and $2 \mathrm{~h}$ of heating and the percent yield of the product can also be determined after each aliquot is removed. The resonances of mesitylene are used to determine the percent yield of the product after these reaction times.

Control Reactions:

Every pair of students is assigned a control reaction. Following the catalytic reaction and characterization procedure described above, the control reaction contains either $\mathrm{RuCl}_{2}\left(\mathrm{PPh}_{3}\right)_{3}$, substrate, mesitylene, (no $\mathrm{K}_{2} \mathrm{CO}_{3}$ ) and acetone, or $\mathrm{K}_{2} \mathrm{CO}_{3}$, substrate, mesitylene, (no $\left.\mathrm{RuCl}_{2}\left(\mathrm{PPh}_{3}\right)_{3}\right)$, and acetone. 


\section{Results and Discussion}

Synthesis and Characterization of $\mathrm{RuCl}_{2}\left(\mathrm{PPh}_{3}\right)_{3}$ :

A typical student isolated yield for the synthesis of $\mathrm{RuCl}_{2}\left(\mathrm{PPh}_{3}\right)_{3}$ is $42 \%$.

$\mathrm{A}{ }^{1} \mathrm{H}$ NMR and ${ }^{31} \mathrm{P}$ NMR of $\mathrm{RuCl}_{2}\left(\mathrm{PPh}_{3}\right)_{3}$ are acquired in $\mathrm{CDCl}_{3}$. NMR samples are prepared in the inert atmosphere glove box. The ${ }^{1} \mathrm{H}$ NMR of $\mathrm{RuCl}_{2}\left(\mathrm{PPh}_{3}\right)_{3}$ shows resonances at $\delta 7.00 \mathrm{ppm}(\mathrm{m}, 15 \mathrm{H})$ and $7.28 \mathrm{ppm}(\mathrm{m}, 30$ $\mathrm{H})$. These protons corresponded to the aromatic protons in triphenylphosphine. The ${ }^{31} \mathrm{P}$ NMR showed resonances at $\delta 30.28 \mathrm{ppm}, 41.62 \mathrm{ppm}$, and $52.152 \mathrm{ppm}$. These resonances are shifted upfield compared to the phosphorous resonance for free triphenylphosphine in $\mathrm{CDCl}_{3}$ solution ( $\left.\delta-4.3 \mathrm{ppm}\right)$. The appearance of new resonances suggests that the triphenylphosphine is coordinated to the ruthenium metal center. The ${ }^{1} \mathrm{H}$ and ${ }^{31} \mathrm{P} \mathrm{NMR}$ of $\mathrm{RuCl}_{2}\left(\mathrm{PPh}_{3}\right)_{3}$ are shown below in Figures 1 and 2. 
Figure 1: $300 \mathrm{MHz}{ }^{1} \mathrm{H}$ NMR of $\mathrm{RuCl}_{2}\left(\mathrm{PPh}_{3}\right)_{3}$ in $\mathrm{CDCl}_{3}$.

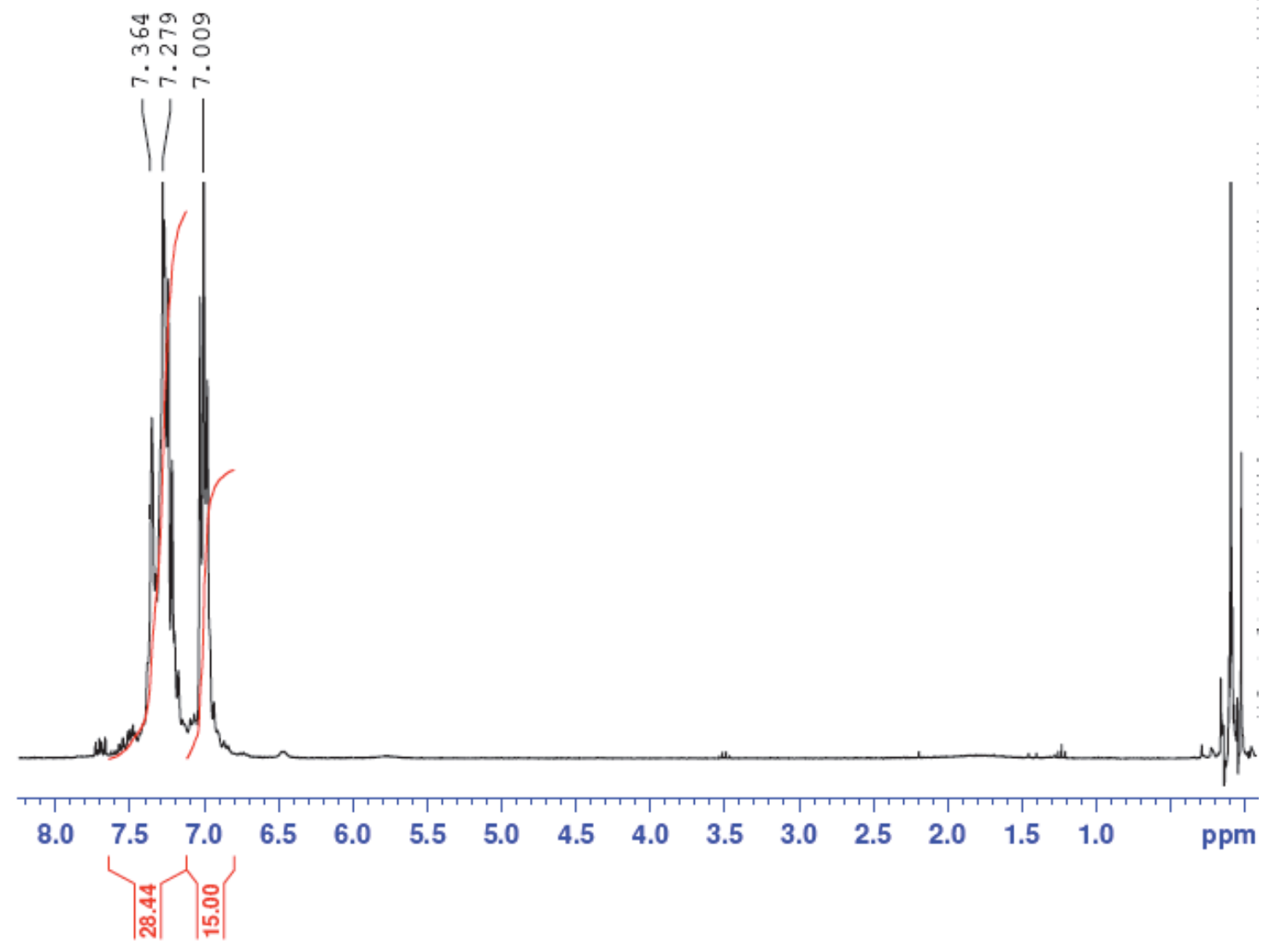


Figure 2: $161.9 \mathrm{MHz}{ }^{31} \mathrm{P} \mathrm{NMR}$ of $\mathrm{RuCl}_{2}\left(\mathrm{PPh}_{3}\right)$ in $\mathrm{CDCl}_{3}$

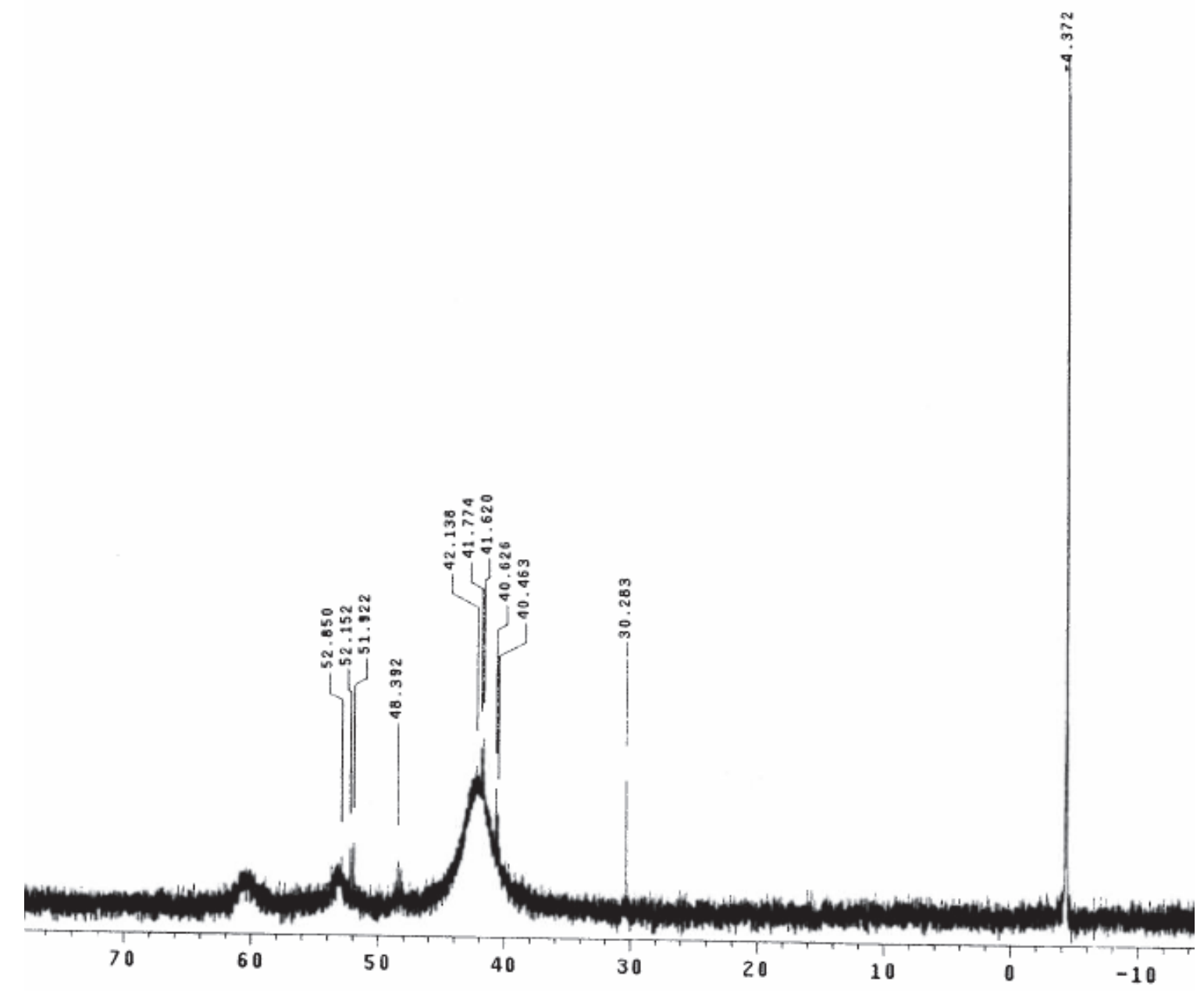

IR data is also collected in the solid phase for $\mathrm{RuCl}_{2}\left(\mathrm{PPh}_{3}\right)_{3}$ and $\mathrm{RuCl}_{3} \cdot \mathrm{xH}_{2} \mathrm{O}$ using an attenuated total reflectance (ATR) attachment. The FTIRATR spectrum of $\mathrm{RuCl}_{3} \cdot \mathrm{xH}_{2} \mathrm{O}$ is collected to show that the starting material is converted to product. The $\mathrm{RuCl}_{3} \cdot \mathrm{xH}_{2} \mathrm{O}$ spectrum (Figure 3) shows the characteristic $\mathrm{O}-\mathrm{H}$ stretch at $3275 \mathrm{~cm}^{-1}$ and the Ru-O stretch at $1581 \mathrm{~cm}^{-1}$. The $\mathrm{Ru}-\mathrm{Cl}$ stretches expected to appear between 300 and $200 \mathrm{~cm}^{-1}$ cannot be observed in this spectrum. (11) The FTIR-ATR spectrum of $\mathrm{RuCl}_{2}\left(\mathrm{PPh}_{3}\right)$ is different than that of $\mathrm{RuCl}_{3} \cdot \mathrm{xH}_{2} \mathrm{O}$ suggesting that a reaction has occurred. The large, broad $\mathrm{O}-\mathrm{H}$ stretch and the high intensity $\mathrm{Ru}-\mathrm{O}$ stretch are no longer seen. 
The appearance of several new peaks not present in the starting material also suggests that a reaction has occurred. In the FTIR-ATR spectrum of the product (Figure 4), the $\mathrm{C}-\mathrm{H}$ aromatic stretches are seen at $3058 \mathrm{~cm}^{-1}$ and the $\mathrm{C}-\mathrm{H}$ bending vibrations are seen at 742 and $693 \mathrm{~cm}^{-1}$. The $\mathrm{C}=\mathrm{C}$ aromatic stretches are seen at 1480 and $1432 \mathrm{~cm}^{-1}$. The Ru-P and $\mathrm{Ru}-\mathrm{Cl}$ stretches are not observed.

Figure 3: FTIR-ATR spectrum of $\mathrm{RuCl}_{3} \cdot \mathrm{xH}_{2} \mathrm{O}$

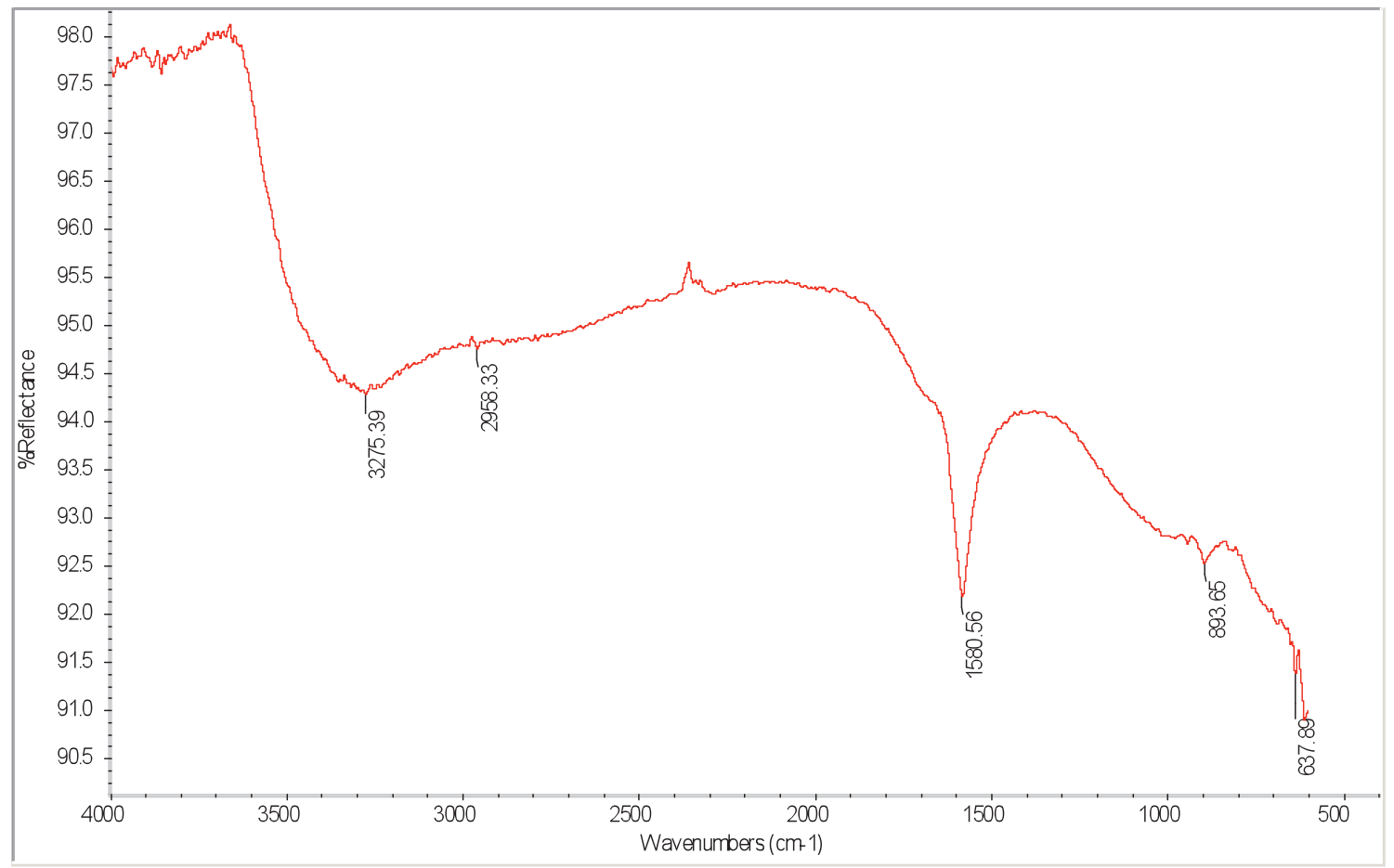


Figure 4: FTIR-ATR spectrum of $\mathrm{RuCl}_{2}\left(\mathrm{PPh}_{3}\right)_{3}$

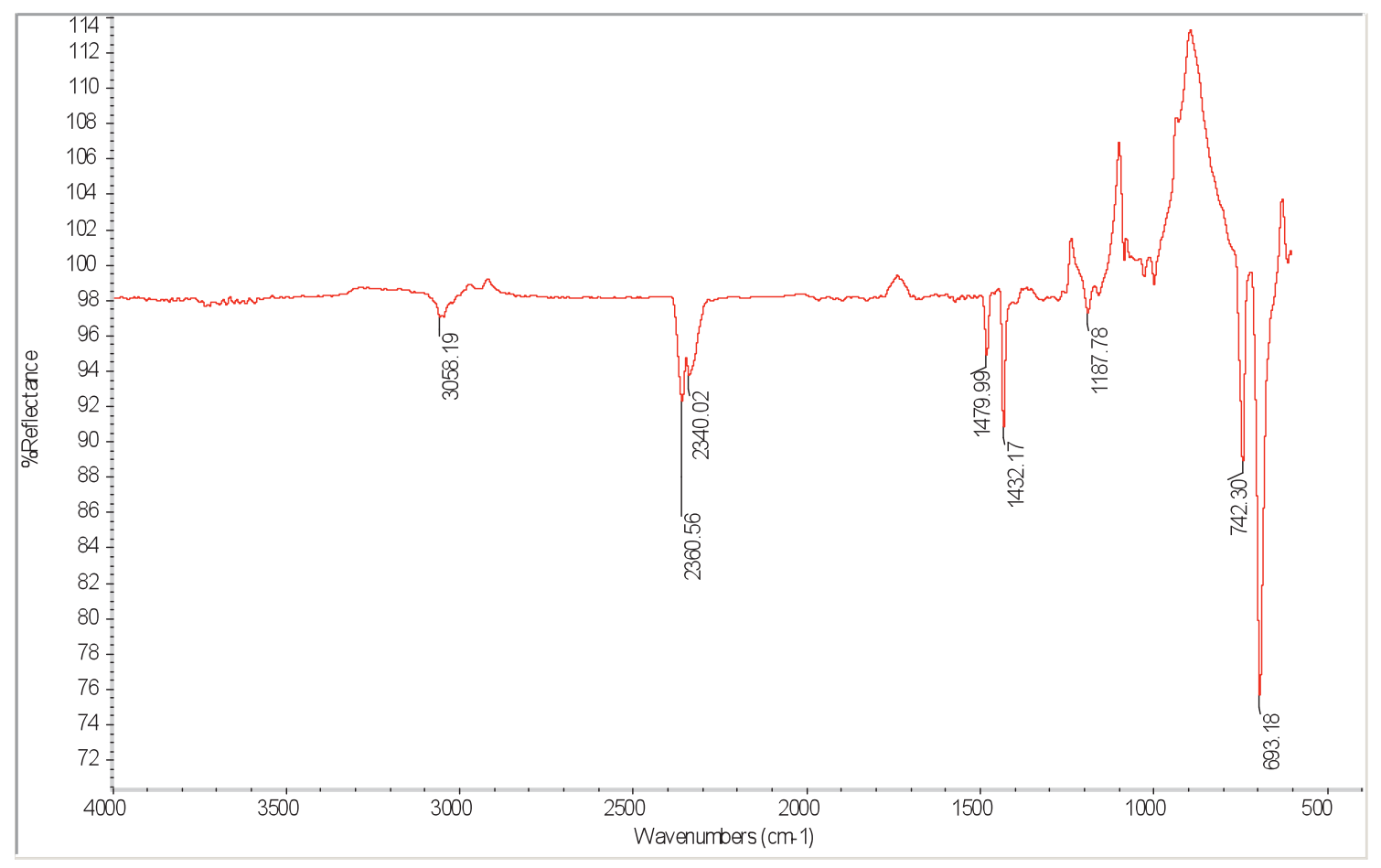

Magnetic susceptibility data is collected for $\mathrm{RuCl}_{2}\left(\mathrm{PPh}_{3}\right)_{3}$ using a Johnson Matthey magnetic susceptibility balance. The $\mu_{\text {eff }}$ was calculated to be $0 \mathrm{BM}$, which is consistent with square pyramidal geometry about the ruthenium center. (12)

Activity of Pre-Catalyst:

Once the $\mathrm{RuCl}_{2}\left(\mathrm{PPh}_{3}\right)_{3}$ is prepared, it is screened for activity for the conversion of 1-phenylethanol to acetophenone in the presence of acetone and $\mathrm{K}_{2} \mathrm{CO}_{3}$ (eq. 4). The precatalyst loading is $10 \mathrm{~mol} \%$.

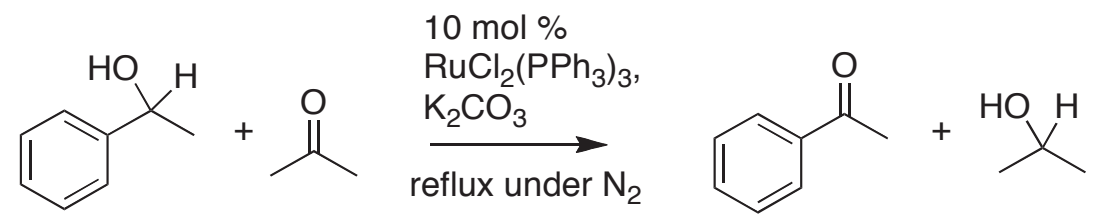

A non-reactive internal standard, mesitylene (1 eq), is added to quantify the percent yield of the acetophenone product. The ${ }^{1} \mathrm{H}$ NMR of mesitylene in $\mathrm{CDCl}_{3}$ 
has a singlet at $\delta 2.32 \mathrm{ppm}$, which integrates to $9 \mathrm{H}$ and a singlet at $\delta 6.84 \mathrm{ppm}$, which integrates to $3 \mathrm{H}$. These resonances do not overlap with the ${ }^{1} \mathrm{H}$ NMR resonances of either the starting material or the product.

A control reaction is also run with no $\mathrm{RuCl}_{2}\left(\mathrm{PPh}_{3}\right)_{3}$ present. The catalytic reaction is also carried out using commercially available $\mathrm{RuCl}_{2}\left(\mathrm{PPh}_{3}\right)_{3}$ purchased from Strem.

The percent yields for the catalytic and control reactions are determined using ${ }^{1} \mathrm{H}$ NMR after reaction times of 1 and 2 hours.

The activity of the catalyst is determined by calculating the turnover frequency (TOF), which is defined in equation 5 :

$$
\mathrm{TOF}=(\text { moles product }) /(\text { moles catalyst }) /(\text { time }(\mathrm{h}))
$$

A higher turnover frequency indicates a more active catalyst.

Student results are summarized in Table 1. Typical ${ }^{1} \mathrm{H}$ NMR spectra in $\mathrm{CDCl}_{3}$ for the catalyzed reactions after 1 hour are shown in Figures 5 and 6. 
Figure 5: $300 \mathrm{MHz}{ }^{1} \mathrm{H}$ NMR of catalyzed reaction after 1 hour using synthesized $\mathrm{RuCl}_{2}\left(\mathrm{PPh}_{3}\right)_{3}$.

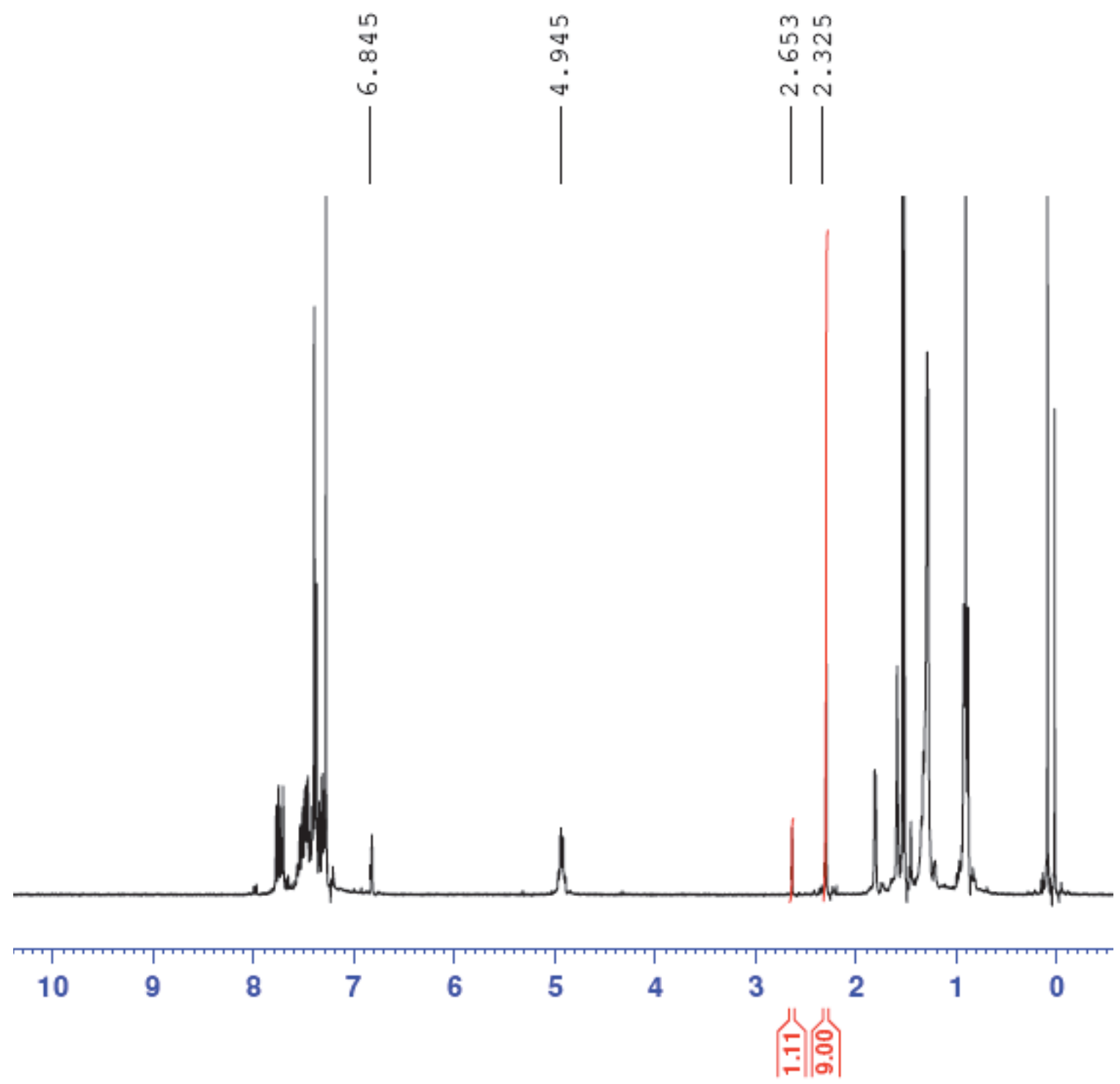


Figure 6: $300 \mathrm{MHz}{ }^{1} \mathrm{H}$ NMR of catalyzed reaction after 1 hour using commercially available $\mathrm{RuCl}_{2}\left(\mathrm{PPh}_{3}\right)_{3}$.

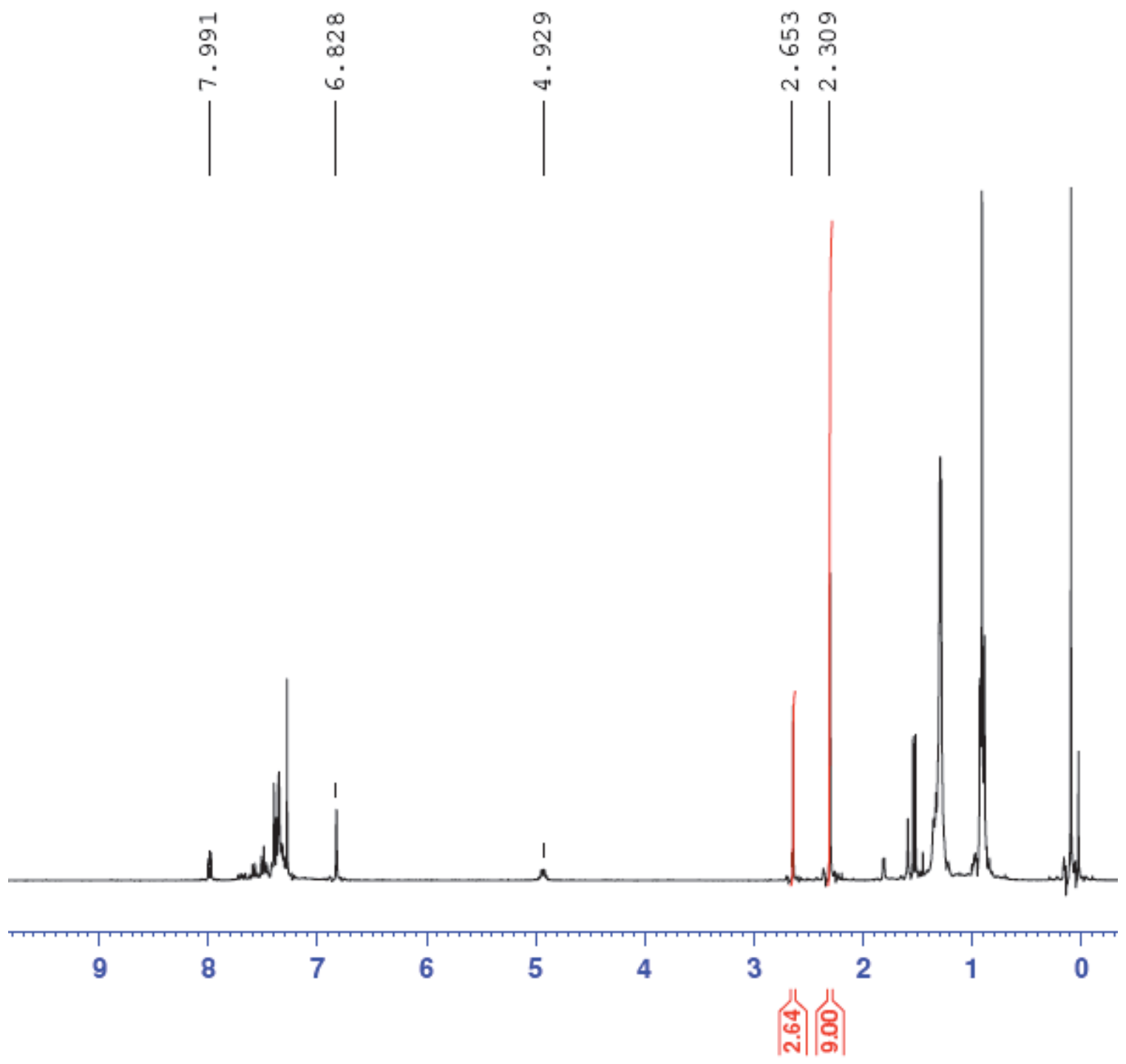


Table 1: Summary of Percent Yield and Turnover frequencies for catalytic and control reactions

\begin{tabular}{|c|c|c|c|}
\hline & TOF (turnovers/h) & \% Yield after $1 \mathrm{~h}$ & \% Yield after $2 \mathrm{~h}$ \\
\hline $\begin{array}{c}\text { Synthesized } \\
\mathrm{RuCl}_{2}\left(\mathrm{PPh}_{3}\right)_{3}\end{array}$ & 3 & 37 & 54 \\
\hline Control Reaction & - & & $<5$ \\
\hline $\begin{array}{c}\text { Commercial } \\
\mathrm{RuCl}_{2}\left(\mathrm{PPh}_{3}\right)_{3}\end{array}$ & 4 & 88 & 88 \\
\hline
\end{tabular}

The data in Table 1 suggests that the catalyst purchased from Strem is more efficient than the prepared catalyst. The work-up in the laboratory did not include any recrystallization steps, which were carried out by the manufacturer. No product resonances were in either ${ }^{1} \mathrm{H}$ NMR spectrum for the control reaction. Thus, $\mathrm{RuCl}_{2}\left(\mathrm{PPh}_{3}\right)_{3}$ is necessary for this transformation.

At the end of the experiment, the students write a lab report in the form of a journal article where they describe their results and include catalytic and control results from other groups.

\section{Conclusions}

A lab experiment is presented for Advanced Inorganic Chemistry students. The students synthesize and characterize $\mathrm{RuCl}_{2}\left(\mathrm{PPh}_{3}\right)_{3}$ and use it as a precatalyst for the oxidation of 1-phenylethanol to acetophenone. The laboratory is completed in three four-hour laboratory periods and serves to introduce students to air-sensitive chemistry and homogenous catalysis.

\section{Special Equipment, Instruments, and Chemicals}

MBraun Inert Atmosphere Glove Box Johnson Matthey Magnetic Susceptibility Balance

Bruker $300 \mathrm{MHz}$ NMR Spectrometer

Rotary evaporator

Avatar 360-FTIR with ATR Attachment 


\author{
Schlenk Line \\ Ruthenium trichloride hydrate \\ dichlorotris(triphenylphosphine)ruthenium(II) \\ Methanol \\ Mesitylene \\ Triphenylphosphine \\ Potassium Carbonate \\ 1-phenylethanol \\ Acetone \\ Diethyl Ether \\ Deuterated Chloroform \\ Celite \\ n-hexane
}

\title{
Hazards
}

All of the organic solvents are flammable. Deutero-chloroform is a carcinogen. Ruthenium (III) chloride hydrate is corrosive to the skin and eyes. All of the reactions and all work ups take place in the hood. Students wear safety glasses/goggles and gloves when working.

\section{Acknowledgements}

JRM would like to thank my Advanced Inorganic Chemistry students at Fairfield University and Inorganic Chemistry students at Boston University who have helped me make this lab a success. JRM would also like to thank the Department of Chemistry and Biochemistry and the College of Arts and Sciences at Fairfield University for their generous financial support of my work. In addition, JRM would like to thank Boston University for a Postdoctoral Faculty Fellowship.

\section{Supporting JCE Online Material}

Supplement

Lab experiment from Course Lab Manual 
Results and Discussion Questions for Lab report

Student notes

Pre-laboratory expectations for the students

CAS Registry Numbers for all chemicals

Hazards and Safety Instructions for Students

Instructor Notes

\section{Notes}

1 Advanced Inorganic Chemistry has both lecture and laboratory components. Physical Chemistry I is a co-requisite for the course.

\section{Literature Cited}

(1) ACS Committee on Professional Training. http://portal.acs.org/portal/acs/corg/content? nfpb=true\& pageLabel=PP TRANSITIONMAIN\&node id=1540\&use $\mathrm{sec}=$ false\&sec url var=region1 \& uuid=a7a1894d-fc61-4749-bb91-436aa1527291 (Accessed January 2010).

(2) Hallman, P.S.; Stephenson, T.A.; Wilkinson, G. Inorg Synth, 1970, 12, 238-240.

(3) Wang, G-Z.; Bäckvall, J.-E. J. Chem. Soc. Chem. Commun, 1992, 337339.

(4) Niewahner, J.H.; Walters, K.A. J. Chem. Ed., 2007, 84, 702-703.

(5) France, M.B.; Uffelman, E.S. J. Chem. Ed., 1999, 76, 661-665.

(6) Zassinovich, G.; Mestroni, G.; Gladiali, S. Chem. Rev., 1992, 92, 10511069.

(7) Sheldon, R.A.; Arends, I.W.C.E. Catalysis by Metal Complexes, 2003, 26 (Advances in Catalytic Activation of Dioxygen by Metal Complexes), 123155. 
(8) (a) Miecznikowski, J.R.; Crabtree, R.H. Polyhedron, 2004, 23, 28572872. (b) Miecznikowski, J.R.; Crabtree, R.H. Organometallics, 2004, $23,629-631$.

(9) Miessler, G.L.; Tarr, D.A. Inorganic Chemistry, $3^{\text {rd }}$ ed. Upper Saddle River, NJ: Pearson Prentice Hall, 2004, 454-555.

(10) Almeida, M.L.S.; Beller, M.; Wang, G.-Z.; Backvall, J.-E. Chem. Eur. J.; 1996, 2, 1533-1536.

(11) Nakamoto, K. Infrared and Raman Spectra of Inorganic and Coordination Compounds, $4^{\text {th }}$ ed. John Wiley \& Sons, New York 1986, 324-342.

(12) LaPlaca, S.J.; Ibers, J.A. Inorg. Chem, 1965, 4, 778-783. 